\title{
Medical Student Knowledge, Attitudes, and Practices Regarding Immunization
}

\author{
Deeva Berera ${ }^{1^{*}}$ and Kimberly M Thompson ${ }^{2,3}$ \\ ${ }^{1}$ Medical Student (Y3), University of Central Florida, College of Medicine, 6850 Lake Nona Blvd, Orlando, FL 32827, USA \\ ${ }^{2}$ Professor of Preventive Medicine and Global Health, University of Central Florida, College of Medicine, Orlando, FL USA \\ ${ }^{3}$ President, Kid Risk, Inc., USA
}

"Corresponding author: Deeva Berera, Medical Student (Y3), University of Central Florida, College of Medicine, 6850 Lake Nona Blvd, Orlando, FL 32827, USA, Tel: (617)680-2836; E-mail: dberera@knights.ucf.edu

Received date: 25 November 2014; Accepted date: 26 January 2015; Published date: 29 January 2015

Copyright: (C) 2015 Berera D, et al. This is an open-access article distributed under the terms of the Creative Commons Attribution License, which permits unrestricted use, distribution, and reproduction in any medium, provided the original author and source are credited.

\begin{abstract}
Physician knowledge and support of vaccines greatly influence patient decisions to get vaccinated, and medical schools can cultivate vaccination knowledge and positive attitudes towards vaccines. We sought to establish a baseline of medical student knowledge, attitudes, and practices about vaccines to identify knowledge gaps, characterize common themes in student beliefs, and determine the need for vaccination education interventions. We administered a survey questionnaire, designed to assess medical student knowledge, attitudes, and practices towards vaccination to second, third, and fourth year medical students at the University of Central Florida, College of Medicine. We surveyed the students within the first two weeks of the start of their respective academic years. We found that student knowledge levels correlated significantly with year and experience delivering immunizations. We estimated mean knowledge scores for second, third, and fourth year students of 55\% (SD 13), 65\% (SD 13), and $74 \%$ (SD 10), respectively. Students expressed positive and supportive attitudes and practices towards vaccination. Our results show low confidence in patient and personal education regarding vaccines, with $40 \%$ of students reporting feeling comfortable answering questions from patients or parents about vaccines, and $29 \%$ reporting their receipt of adequate vaccination education in medical school. This study provides a foundation to initiate the development of comprehensive vaccination education for medical students. Further studies should expand the survey to other medical institutions to inform the creation of immunization competencies for all US medical students and develop an educational intervention to address the knowledge gaps we identified.
\end{abstract}

Keywords: Medical education; Immunization; Survey

\section{Introduction}

Vaccination represents an essential component of preventive medicine. Despite the well-established benefits of immunization, missed-opportunities for vaccination remain a public health concern [1-3]. Previous research shows that physician attitudes towards vaccines can directly influence patient decisions to accept or reject vaccination [4,5]. Inadequate physician knowledge regarding vaccines and patient eligibility for vaccination can further reduce vaccination coverage rates [6].

Experience with vaccines prior to and during medical school may impact future physician recommendations about immunizations to patients. A recent study investigating the immunization requirements of US health professional schools reported that $100 \%$ of surveyed medical schools required students to receive specified vaccines prior to matriculation [7]. During their clinical years, medical students may discuss and recommend vaccines as part of their pediatric and internal medicine clerkships, which occur sometime in their third or fourth year. Studies conducted on medical students in Canada and Germany identified the importance of assessing student knowledge of vaccines to support the creation of targeted educational interventions to help prepare students for patient interactions related to immunization $[8,9]$.

Physician attitudes and beliefs may also impact patient care. For example, one study reported a strong correlation between healthcare provider recommendations and their own personal practices (e.g., receipt of influenza vaccine) and knowledge regarding vaccination (e.g., beliefs about vaccine efficacy) $[10,11]$. Some studies recognized the potential value of educational interventions targeted towards medical students, specifically with regard to influenza vaccination $[12,13]$. The expansion of interventions considered by these efforts to encompass other vaccines and vaccine concepts more broadly represents an important opportunity to improve vaccine acceptance and use. In addition, the development of immunization competencies, similar to those created by the Canadian Ministry of Health, may improve overall vaccine outcomes [14].

To date, no studies comprehensively examine the knowledge, attitudes, and practices of United States (US) medical students with respect to receiving and recommending vaccines. In this study, we performed a baseline assessment to identify the needs of medical students in a new U.S. medical school regarding formal vaccination education. The results of the survey demonstrate the impact of current medical school curricula and identify existing knowledge variances across the span of three classes. The survey also provides valuable information about medical student exposure to preventive medicine practices and their influence on attitudes towards vaccination. These results may inform the creation of an educational tool to better train medical students. 


\section{Methods}

\section{Study design}

We administered a survey questionnaire to students at the University of Central Florida, College of Medicine (UCF COM) within the first two weeks of the start of their academic years 2,3 , and 4 . We selected these study populations to evaluate the impact of the first three years of curricula and to establish a baseline of student knowledge, attitudes, and practices related to vaccines.

\section{Survey design}

We developed a 50-item, web-based questionnaire using the Qualtrics $^{\oplus}$ online survey tool. We obtained permission to use knowledge, attitude, and practice questions from a previously validated instrument used in a study in Canada [8]. We developed additional questions based on our review of the literature and current vaccination guidelines. The survey questionnaire included four sections that addressed student: (1) knowledge of pediatric and adult vaccination topics and guidelines, (2) attitudes towards vaccination (including vaccination policies and the utility of vaccines), (3) practices (including personal uptake of vaccines and immunization resources used to educate themselves and/or patients), and (4) demographics (to characterize student exposure to preventive medicine practices). The questionnaire consisted of 15 true/false knowledge questions, 4 multiple-choice knowledge questions, 18 attitude statements with agreement assessed using a Likert-scale, 5 personal-practice questions assessed using a Likert scale for importance, and 8 demographic questions $(6$ multiple-choice and 2 open-ended) (instrument available from the authors upon request). We created an overall knowledge score for each student by adding the total correct answers to the 15 true/false and 4 multiple-choice knowledge questions (i.e., 19 questions from a survey developed and validated by the Canadian Center for Vaccinology for use on health professional students [8]).

\section{Survey distribution}

We administered the survey during a structured class time for a required session within the first two weeks of the academic year. This timing implies that all students completed their pre-clinical coursework on microbiology and immunology prior to the survey, with Y4 students also completing their required clinical clerkships for both internal medicine and pediatrics. We gave students a maximum of 30 minutes to complete the survey and instructed them not to use web-based resources, books, reference materials, or other supplemental aids. All participants received $\$ 5$ compensation for their participation.

\section{Data analysis}

We performed all statistical analyses using SPSS 21.0" (IBM; Chicago, IL). We examined the responses to the open-ended questions using thematic content analysis. We computed an overall knowledge score by calculating the percentage of knowledge questions answered correctly. Knowledge scores reflect competence of general immunization information (routine guidelines, contraindications), specific vaccines and vaccine preventable diseases, and recommendations for special populations [8]. We reported frequencies and percentages for categorical variables (gender, classes, demographics. We used chi-square tests to report between-group comparisons of categorical variables. We expressed ordinal variables as median (minimum-maximum), and used Mann-Whitney $U$ tests or Kruskal-Wallis tests as appropriate for between-group comparisons. We reported means \pm Standard Deviation (SD) and with 95\% Confidence Intervals (CI) for normally distributed continuous variables. We made between-group comparisons of continuous variables using independent samples t-tests or analysis of variance (ANOVA). We performed all follow-up pairwise comparisons using a Bonferroni correction. We used two-sided tests for all statistical analyses and considered p-values less than 0.05 as statistically significant.

\section{Results}

\section{Demographics}

We administered the questionnaire to 232 students and received 194 completed surveys (84\%). As shown in Table 1, we received responses from 84 (89\%) Y2 students, 77 (99\%) Y3 students, and 33 (58\%) Y4 students (Table 1) with a mean age of 25.26 years (SD 2.34).

\begin{tabular}{|c|c|c|c|}
\hline UCF COM Class & Y2 & Y3 & Y4 \\
\hline $\mathrm{n}$ respondents/n class $(\%)$ & $84 / 94(89)$ & 77/78 (99) & $33 / 57(58)$ \\
\hline Age (mean, SD) & $24.6(2.2)$ & $25.7(2.5)$ & $26(2.0)$ \\
\hline Gender & & & \\
\hline Male, n (\%) & $45(54)$ & $37(48)$ & $12(36)$ \\
\hline Female, $\mathrm{n}(\%)$ & $39(46)$ & $40(52)$ & $21(64)$ \\
\hline Have children (\%) & $4(5)$ & $6(8)$ & $3(9)$ \\
\hline $\begin{array}{ll}\text { Experience } & \text { delivering } \\
\text { immunizations (\%) } & \end{array}$ & $7(8)$ & $6(8)$ & $12(36)$ \\
\hline
\end{tabular}

Table 1: Demographic characteristics of study participants.

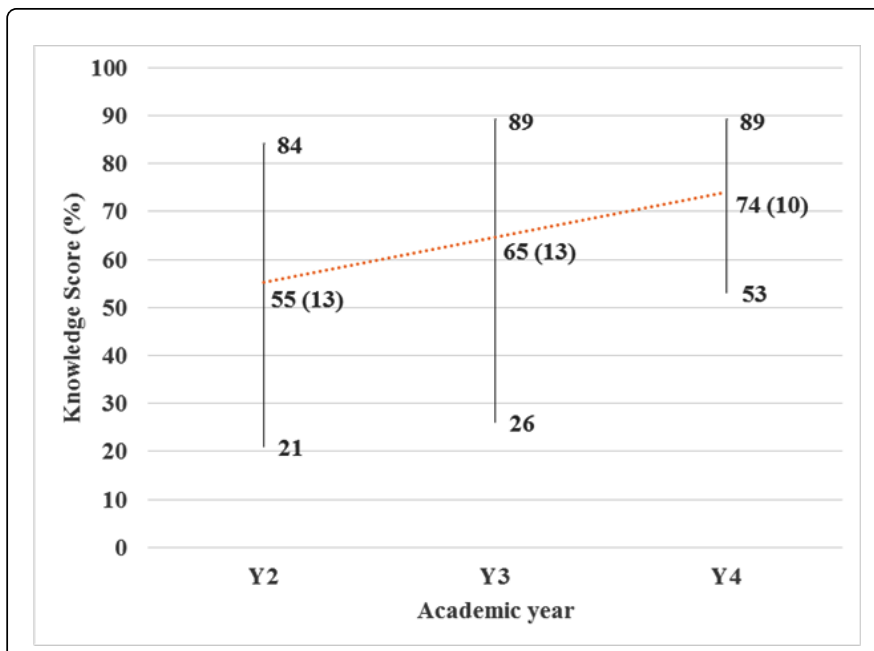

Figure 1: Distribution of knowledge scores by class showing the minimum, maximum, and mean connected by lines with the standard deviation (SD). 
Citation: Berera D, Thompson KM (2015) Medical Student Knowledge, Attitudes, and Practices Regarding Immunization. J Vaccines Vaccin 6:

Page 3 of 6

\begin{tabular}{|c|c|c|c|c|c|}
\hline & $\begin{array}{l}\text { All respondents } \\
(\mathrm{n}=194) \\
n(\%)\end{array}$ & $\begin{array}{l}Y 2 \\
(n=84) \\
n(\%)\end{array}$ & $\begin{array}{l}\text { Y3 } \\
(n=77) \\
n(\%)\end{array}$ & $\begin{array}{l}Y 4 \\
(n=33) \\
n(\%)\end{array}$ & $\begin{array}{l}\text { Association with class year } \\
\text { ( } p \text {-value) }\end{array}$ \\
\hline \multicolumn{6}{|c|}{ Mild illness, with fever, is a reason to withhold vaccinations. } \\
\hline $\begin{array}{l}\text { True } \\
\text { False* } \\
\text { Don't Know }\end{array}$ & $\begin{array}{l}74(38) \\
99(51) \\
21(11)\end{array}$ & $\begin{array}{l}40(47) \\
36(43) \\
8(10)\end{array}$ & $\begin{array}{l}31(40) \\
33(43) \\
13(17)\end{array}$ & $\begin{array}{l}3(9) \\
30(91) \\
0(0)\end{array}$ & 0.02 \\
\hline \multicolumn{6}{|c|}{ Routine childhood vaccines can be given to a child taking antibiotics for an ear infection. } \\
\hline $\begin{array}{l}\text { True }^{*} \\
\text { False } \\
\text { Don't Know }\end{array}$ & $\begin{array}{l}86(45) \\
53(27) \\
55(28)\end{array}$ & $\begin{array}{l}33(39) \\
25(30) \\
26(31)\end{array}$ & $\begin{array}{l}30(39) \\
21(27) \\
26(34)\end{array}$ & $\begin{array}{l}23(70) \\
7(21) \\
3(9)\end{array}$ & 0.03 \\
\hline \multicolumn{6}{|c|}{ Current scientific evidence supports associations between vaccines and chronic conditions such as autism and multiple sclerosis. } \\
\hline $\begin{array}{l}\text { True } \\
\text { False* } \\
\text { Don't Know }\end{array}$ & $\begin{array}{l}46(24) \\
127(65) \\
21(11)\end{array}$ & $\begin{array}{l}31(37) \\
45(54) \\
8(9)\end{array}$ & $\begin{array}{l}15(19) \\
49(64) \\
13(17)\end{array}$ & $\begin{array}{l}0(0) \\
33(100) \\
0(0)\end{array}$ & 0.04 \\
\hline \multicolumn{6}{|c|}{ Vaccines are $100 \%$ effective. } \\
\hline $\begin{array}{l}\text { True } \\
\text { False* } \\
\text { Don't Know }\end{array}$ & $\begin{array}{l}4(2.1) \\
186(96) \\
4(2.1)\end{array}$ & $\begin{array}{l}2(2) \\
79(94) \\
3(4)\end{array}$ & $\begin{array}{l}1(1) \\
75(98) \\
1(1)\end{array}$ & $\begin{array}{l}1(3) \\
32(97) \\
0(0)\end{array}$ & $<0.001$ \\
\hline \multicolumn{6}{|c|}{ Unvaccinated people with subclinical symptoms of influenza can spread the disease to others. } \\
\hline $\begin{array}{l}\text { True* } \\
\text { False } \\
\text { Don't Know }\end{array}$ & $\begin{array}{l}181(93) \\
6(3) \\
7(4) \\
\end{array}$ & $\begin{array}{l}78(93) \\
2(2) \\
4(5)\end{array}$ & $\begin{array}{l}71(92) \\
3(4) \\
3(4)\end{array}$ & $\begin{array}{l}32(97) \\
1(3) \\
0(0)\end{array}$ & $<0.001$ \\
\hline \multicolumn{6}{|c|}{ It is required by law in the United States to vaccinate your child. } \\
\hline $\begin{array}{l}\text { True } \\
\text { False } \\
\text { Don't Know }\end{array}$ & \begin{tabular}{|l}
$16(8)$ \\
$164(85)$ \\
$14(7)$
\end{tabular} & $\begin{array}{l}6(7) \\
71(85) \\
7(8)\end{array}$ & $\begin{array}{l}6(8) \\
64(83) \\
7(9)\end{array}$ & $\begin{array}{l}2(6) \\
29(88) \\
0(0)\end{array}$ & $<0.001$ \\
\hline \multicolumn{6}{|c|}{ The Food and Drug Administration (FDA) approval process for vaccines is the same as that for drugs. } \\
\hline $\begin{array}{l}\text { True } \\
\text { False } \\
\text { Don't Know }\end{array}$ & $\begin{array}{l}87(45) \\
53(27) \\
54(28)\end{array}$ & $\begin{array}{l}39(46) \\
22(26) \\
23(27)\end{array}$ & \begin{tabular}{|l}
$35(45)$ \\
$19(25)$ \\
$23(30)$
\end{tabular} & $\begin{array}{l}13(39) \\
12(36) \\
8(24)\end{array}$ & 0.43 \\
\hline
\end{tabular}

Table 2: Responses to selected knowledge questions overall and by year with a comparison of response by class year. ${ }^{*}$ Indicates correct answer.

\section{Knowledge of vaccination guidelines and contraindications}

Results of the 19-item knowledge assessment demonstrated significant variation between class years in immunization knowledge (Figure 1). The $13 \%$ of students with experience delivering immunizations performed significantly better than their peers on the knowledge assessment $(70 \%$ vs. $60 \%, \mathrm{p}<0.001)$. Neither gender nor having children significantly impacted mean knowledge scores.

With regard to specific knowledge questions, the majority of students $(65 \%)$ correctly identified the lack of scientific evidence linking vaccines to chronic conditions such as autism and multiple sclerosis. The number of students who incorrectly assumed a link existed between vaccines and chronic conditions dramatically decreased between second, third, and fourth year classes (37\%, 19\%, and $0 \%$, respectively) (Table 2 ).

\section{Attitudes towards vaccines and perceived importance of vaccination}

The results showed significant correlation between student attitudes toward improving immunization coverage levels and their performance on the knowledge assessment $(\mathrm{p}=0.014)$. We also found that students who agreed that improving immunization coverage is important received a higher mean knowledge score (63\%, SD 14) than those who disagreed (45\%, SD 3). Overall, $94 \%$ of students agreed that educating patients/parents about vaccines is an important way to increase vaccine coverage rates, while $40 \%$ of students felt comfortable addressing patient/parent concerns about vaccines. The results showed a strong correlation between student confidence addressing patient concerns and their mean knowledge scores $(p=0.019)$. Less than onethird (29\%) of participants reported receiving adequate education about vaccines during medical school. Students with prior experience delivering immunizations (13\%) reported significantly more confidence in their ability to address patient/parent concerns regarding vaccination $(\mathrm{p}=0.019)$. Nearly all students $(>92 \%)$ agreed 
Citation: Berera D, Thompson KM (2015) Medical Student Knowledge, Attitudes, and Practices Regarding Immunization. J Vaccines Vaccin 6:

Page 4 of 6

about the importance of fully immunizing all children and over half (55\%) agreed that physicians can reduce parental stress by spreading necessary vaccines over several visits (i.e. by adhering to alternative schedules, Table 3).

The UCF COM requires influenza vaccination and provides it free of cost for all medical students. When asked if they would choose not to receive the influenza vaccine if required to pay for it, we found that $24 \%$ of students agreed with this statement (Table 3 ). When asked about the importance of requiring influenza immunization for all healthcare workers, $75 \%$ of all students rated this practice as very important and no respondents rated it as unimportant.

\begin{tabular}{|c|c|c|c|c|}
\hline & $\begin{array}{l}\text { All respondents } \\
(\mathrm{n}=194) \\
\mathrm{n}(\%)\end{array}$ & $\begin{array}{l}Y 2 \\
(n=84) \\
n(\%)\end{array}$ & $\begin{array}{l}Y 3 \\
(n=77) \\
n(\%)\end{array}$ & $\begin{array}{l}Y 4 \\
(n=33) \\
n(\%)\end{array}$ \\
\hline \multicolumn{5}{|c|}{ Media coverage regarding vaccines and chronic diseases has increased my concerns about the safety of vaccines. } \\
\hline $\begin{array}{l}\text { Strongly disagree/disagree } \\
\text { Neither agree nor disagree } \\
\text { Strongly agree/agree }\end{array}$ & $\begin{array}{l}131(67) \\
25(13) \\
38(20)\end{array}$ & $\begin{array}{l}67(80) \\
10(12) \\
7(8)\end{array}$ & $\begin{array}{l}60(78) \\
12(16) \\
5(6)\end{array}$ & $\begin{array}{l}30(91) \\
3(9) \\
0(0)\end{array}$ \\
\hline \multicolumn{5}{|c|}{ Improving immunization coverage levels is important. } \\
\hline $\begin{array}{l}\text { Strongly disagree/disagree } \\
\text { Neither agree nor disagree } \\
\text { Strongly agree/agree }\end{array}$ & $\begin{array}{l}4(2) \\
8(4) \\
182(4)\end{array}$ & $\begin{array}{l}3(4) \\
2(2) \\
79(94)\end{array}$ & $\begin{array}{l}1(1) \\
5(7) \\
71(92)\end{array}$ & $\begin{array}{l}0(0) \\
1(3) \\
32(97)\end{array}$ \\
\hline \multicolumn{5}{|c|}{ Vaccination education is only important for medical students pursuing a career in primary care. } \\
\hline $\begin{array}{l}\text { Strongly disagree/disagree } \\
\text { Neither agree nor disagree } \\
\text { Strongly agree/agree }\end{array}$ & $\begin{array}{l}167(86) \\
6(3) \\
21(11)\end{array}$ & $\begin{array}{l}77(91) \\
3(4) \\
4(5)\end{array}$ & $\begin{array}{l}62(80) \\
2(3) \\
13(17)\end{array}$ & $\begin{array}{l}28(85) \\
1(3) \\
4(12)\end{array}$ \\
\hline \multicolumn{5}{|c|}{ I would not get my annual influenza vaccine if I had to pay for it. } \\
\hline $\begin{array}{l}\text { Strongly disagree/disagree } \\
\text { Neither agree nor disagree } \\
\text { Strongly agree/agree }\end{array}$ & $\begin{array}{l}112(58) \\
36(18) \\
46(24)\end{array}$ & $\begin{array}{l}46(55) \\
14(17) \\
24(28)\end{array}$ & $\begin{array}{l}45(58) \\
17(22) \\
15(20)\end{array}$ & $\begin{array}{l}21(64) \\
5(15) \\
7(21)\end{array}$ \\
\hline \multicolumn{5}{|c|}{ It is important that all adults are fully immunized. } \\
\hline $\begin{array}{l}\text { Strongly disagree/disagree } \\
\text { Neither agree nor disagree } \\
\text { Strongly agree/agree }\end{array}$ & $\begin{array}{l}4(2) \\
21(11) \\
169(87)\end{array}$ & $\begin{array}{l}1(1) \\
7(8) \\
76(91)\end{array}$ & $\begin{array}{l}0(0) \\
8(10) \\
69(90)\end{array}$ & $\begin{array}{l}3(9) \\
6(18) \\
24(73)\end{array}$ \\
\hline \multicolumn{5}{|c|}{ Parental stress can be reduced by spreading necessary childhood vaccines over several visits. } \\
\hline $\begin{array}{l}\text { Strongly disagree/disagree } \\
\text { Neither agree nor disagree } \\
\text { Strongly agree/agree }\end{array}$ & $\begin{array}{l}41(21) \\
47(24) \\
106(55)\end{array}$ & $\begin{array}{l}19(23) \\
19(23) \\
46(54)\end{array}$ & $\begin{array}{l}14(18) \\
19(25) \\
44(57)\end{array}$ & $\begin{array}{l}8(24) \\
9(27) \\
16(49)\end{array}$ \\
\hline \multicolumn{5}{|c|}{ Educating patients/parents about vaccines is an important way to increase vaccine coverage rates. } \\
\hline $\begin{array}{l}\text { Strongly disagree/disagree } \\
\text { Neither agree nor disagree } \\
\text { Strongly agree/agree }\end{array}$ & $\begin{array}{l}1(1) \\
10(5) \\
183(94)\end{array}$ & $\begin{array}{l}0(0) \\
3(4) \\
81(96)\end{array}$ & $\begin{array}{l}0(0) \\
3(4) \\
74(96)\end{array}$ & $\begin{array}{l}1(3) \\
4(12) \\
28(85)\end{array}$ \\
\hline \multicolumn{5}{|c|}{ I am comfortable responding to the questions patients/parents have about vaccines and vaccine side effects. } \\
\hline $\begin{array}{l}\text { Strongly disagree/disagree } \\
\text { Neither agree nor disagree } \\
\text { Strongly agree/agree }\end{array}$ & $\begin{array}{l}63(32) \\
54(28) \\
77(40)\end{array}$ & $\begin{array}{l}27(32) \\
30(36) \\
27(32)\end{array}$ & $\begin{array}{l}29(38) \\
17(22) \\
31(40)\end{array}$ & $\begin{array}{l}7(21) \\
7(21) \\
19(58)\end{array}$ \\
\hline \multicolumn{5}{|c|}{ I have received adequate education about vaccines and vaccinology during medical school. } \\
\hline $\begin{array}{l}\text { Strongly disagree/disagree } \\
\text { Neither agree nor disagree } \\
\text { Strongly agree/agree }\end{array}$ & $\begin{array}{l}70(36) \\
67(35) \\
57(29)\end{array}$ & $\begin{array}{l}30(36) \\
32(38) \\
22(26)\end{array}$ & $\begin{array}{l}38(49) \\
23(30) \\
16(21)\end{array}$ & $\begin{array}{l}2(6) \\
12(36) \\
19(58)\end{array}$ \\
\hline
\end{tabular}

Table 3: Responses to selected attitudinal questions.

\section{Discussion}

Our baseline assessment of medical student knowledge, attitudes, and practices towards vaccination revealed several important findings.
First, medical students currently acquire knowledge of vaccination guidelines and experience with vaccines over the course of their three core educational years, as shown by the increase in knowledge scores 
between class years. With vaccinology not considered a formal discipline or an assessed core competency in US medical education curricula, medical schools generally scatter vaccination concepts in basic science immunology and microbiology coursework and throughout required clerkships. Not surprisingly, we found that fourth year students showed the most knowledge overall, most likely reflecting the impact of their experiences in clerkships, since all UCF COM students complete pediatrics and internal medicine rotations in their third year. Students who reported experience delivering vaccines performed significantly better on the knowledge assessment and felt more confident in their ability to respond to patient/parent concerns regarding vaccination than those without experience. This finding suggests the importance of creating opportunities for all students to deliver vaccines while in medical school, possibly via immunization clinics, to further increase student knowledge levels and confidence. Unfortunately, given the timing of the research project, we did not perform an assessment of students at the end of their fourth year, which would provide an overall perspective on the impact of the complete medical education received by all students at the end of their training. Future studies should consider measuring student knowledge, attitudes, and practice at the end of the academic years.

Second, the vast majority of students reported highly positive attitudes and supportive practices towards vaccination, as shown by their sentiments towards the importance of vaccination and their willingness to receive influenza vaccination despite the associated cost. Combined with our findings about the lack of confidence among many students in addressing patient/parent concerns and in the amount of vaccination education they reported receiving, these results suggest the likely receptivity of medical students to educational interventions related to immunization. Efforts to standardize immunization training for medical students as part of their curriculum would most likely benefit from reinforcement by the development of immunization core competencies. The introduction of specific learning modalities and core competencies regarding vaccination may effectively address this issue and boost student confidence in the quality of their own personal education as well as their ability to educate patients.

Third, our findings related to implied student acceptability of alternative schedules suggest the need for discussions regarding the value of evidence-based risk communication. While the majority of students recognized the importance of fully immunizing children, $21 \%$ confidently disagreed about the concept of reducing parental stress through the use of alternative immunization schedules. Unfortunately this question in our survey conflated parental stress and the acceptability of the alternative schedule, and future studies should consider separating these points. Recent studies suggest that patient concerns regarding vaccines and the use of non-physician resources play an important role in choices to follow an alternative immunization schedule, while communication from physicians play a significant role in promoting adherence to Advisory Committee on Immunization Practices (ACIP) schedules $[15,16]$. Educating medical students about the importance of schedule adherence and approaches to risk communication could prove particularly important during the pre-clinical and clinical years [17].

Finally, in addition to limitations mentioned previously with respect to the timing of our survey and some of the questions, we note some additional limitations. First, we surveyed a relatively small population of students in a new medical school. Other populations of students may show different results, and consequently we suggest the need for further study of other medical school student populations. Second, although we used some validated questions from other studies, we piloted the survey questionnaire during this study, which limited our ability to fully evaluate the questions or compare the results between different populations.

\section{Conclusions}

This study provides an important foundation to support the development of comprehensive vaccination education for medical students. We highlight differences in knowledge levels between medical student classes and the influence of student experience delivering vaccines on student knowledge and confidence. Medical students positively view vaccination education, and they would likely be receptive to more education and training related to vaccines. Further studies should extend the survey to other medical school populations and explore the development of an educational intervention to address the identified knowledge gaps and boost student confidence about vaccines. We also suggest that medical institutions should consider standardizing a set of core competencies for immunization for all US medical students.

\section{Acknowledgments}

We thank Teresa Johnson, PhD (UCF COM) for support with statistical analysis; Elizabeth Smock, EdD (UCF COM) for inputting and disseminating the survey; Colleen Moran-Bano, MD, Lori A. Boardman, MD, ScM, Maria L. Cannarozzi, MD, and Analia Castiglioni, MD (UCF COM) for support with survey administration; Caridad Hernandez, MD (UCF COM), Shelly McNeil, MD (Canadian Center for Vaccinology), Lorine Pelly, MD (University of Manitoba), Paul Offit, MD (Children's Hospital of Philadelphia), Stephen L. Cochi, MD, MPH (Centers for Disease Control and Prevention), and William M. DeCampli, MD, PhD (Arnold Palmer Hospital for Children) for useful discussion on the project.

\section{Funding/Support}

The University of Central Florida College of Medicine (UCF COM) Focused Individualized Research Experience (FIRE) module funded this research.

\section{Ethical Approval}

The University of Central Florida Institutional Review Board deemed this study exempt on 4/26/2013.

\section{References}

1. Link-Gelles R, Chamberlain AT, Schulkin J, Ault K, Whitney E, et al. (2012) Missed opportunities: a national survey of obstetricians about attitudes on maternal and infant immunization. Matern Child Health J 16: 1743-1747.

2. Holman DM, Benard V, Roland KB, Watson M, Liddon N, et al. (2014) Barriers to human papillomavirus vaccination among US adolescents: a systematic review of the literature. JAMA Pediatr 168: 76-82.

3. Wong CA, Taylor JA, Wright JA, Opel DJ, Katzenellenbogen RA (2013) Missed opportunities for adolescent vaccination, 2006-2011. J Adolesc Health 53: 492-497.

4. Johnson DR, Nichol KL, Lipczynski K (2008) Barriers to adult immunization. Am J Med 121: S28-35. 
Citation: Berera D, Thompson KM (2015) Medical Student Knowledge, Attitudes, and Practices Regarding Immunization. J Vaccines Vaccin 6:

Page 6 of 6

5. Freed GL, Clark SJ, Cowan AE, Coleman MS (2011) Primary care physician perspectives on providing adult vaccines. Vaccine 29: 1850-1854.

6. Smailbegovic MS, Laing GJ, Bedford H (2003) Why do parents decide against immunization? The effect of health beliefs and health professionals. Child Care Health Dev 29: 303-311.

7. Lindley MC, Lorick SA, Spinner JR, Krull AR, Mootrey GT, et al. (2011) Student vaccination requirements of U.S. health professional schools: a survey. Ann Intern Med 154: 391-400.

8. Pelly LP, Pierrynowski Macdougall DM, Halperin BA, Strang RA, Bowles SK, et al. (2010) THE VAXED PROJECT: an assessment of immunization education in Canadian health professional programs. BMC Med Educ 10: 86.

9. Betsch C, Wicker S (2012) E-health use, vaccination knowledge and perception of own risk: drivers of vaccination uptake in medical students. Vaccine 30: 1143-1148.

10. Nichol KL, Zimmerman R (2001) Generalist and subspecialist physicians knowledge, attitudes, and practices regarding influenza and pneumococcal vaccinations for elderly and other high-risk patients: nationwide survey. Arch Intern Med 161: 2702-2708.
11. Szilagyi PG, Rodewald LE (1996) Missed opportunities for immunizations: a review of the evidence. J Public Health Manag Pract 2: 18-25.

12. Afonso N, Kavanaugh M, Swanberg S (2014) Improvement in attitudes toward influenza vaccination in medical students following an integrated curricular intervention. Vaccine 32: 502-506.

13. Hernandez-Garcia I, Valero LF (2013) Practices, beliefs and attitudes associated with support for mandatory influenza vaccination among Spanish medical students. Vaccine 32: 207-208.

14. Public Health Agency of Canada (2008) Immunization competencies for health professionals. Ottawa: Authority of the Minister of Health.

15. Wheeler M, Buttenheim AM (2013) Parental vaccine concerns, information source, and choice of alternative immunization schedules. Hum Vaccin Immunother 9: 1782-1789.

16. Esposito S, Principi N, Cornaglia G; ESCMID Vaccine Study Group (EVASG) (2014) Barriers to the vaccination of children and adolescents and possible solutions. Clin Microbiol Infect 20 Suppl 5: 25-31.

17. Larson HJ, Cooper LZ, Eskola J, Katz SL, Ratzan S (2011) Addressing the vaccine confidence gap. Lancet 378: 526-535. 